\title{
Accountants' Awareness And Perceptions About Assurance On XBRL Financial Statements
}

Roopa Venkatesh, University of Nebraska at Omaha, USA

Jack Armitage, University of Nebraska at Omaha, USA

\begin{abstract}
The purpose of this study is to gather information about accountants' and auditors' level of knowledge of XBRL and their perceptions about the importance of providing assurance and the level of assurance needed. An online survey questionnaire was used to gather data from CPAs at all levels of experience and was open from December 2009 through February 2010. The survey gathered information about the participants' level of knowledge and awareness about XBRL, and their perceptions about the importance, relevance, and need for assurance on XBRL financial information. The results suggest that accountants and auditors believe that assurance on XBRL financial statements is important and will improve the accuracy and reliability of the XBRL tagged financial statements. Participants were also asked to rank the importance of assurance criteria on XBRL financial statements such as assurance on the accuracy, completeness, existence, proper taxonomies, proper extensions, valid extensions and validity and well-formedness. The results show that participants ranked assurance on the accuracy and completeness assertions as being most important and assurance on validity and well-formedness being the least important. The findings have important implications for the audit profession, as the implementation of XBRL has the potential to not only expand the role of the auditor to include auditing their client's application of XBRL tags, but might also influence the cost and time involved to conduct audit services.
\end{abstract}

Keywords: XBRL; XBRL Financial Statements; Financial Statement Assurance; Interactive Data, Assurance

\section{INTRODUCTION}

$e$

Xtensible Business Reporting Language (XBRL) is rapidly revolutionizing the way business information (which includes but is not limited to financial statements) is being exchanged globally (Hodge et al.; 2004; Gray and White, 2005; Plumlee and Plumlee, 2008; Bartley et al., 2011). On January 30, 2009, the Securities and Exchange Commission (SEC) announced its adoption of Interactive Data to Improve Financial Reporting ${ }^{[1]}$ (SEC, 2009), which requires public filers to provide a supplemental exhibit to their financial statements (including footnotes) in XBRL. The largest 500 public companies were required to comply with this new requirement starting on June 15, 2009, and the phase-in of this requirement for the other filers is to be completed on June 15, 2011. This initiative demonstrates the SEC's firm commitment to implementing XBRL in the U.S. In order to encourage participation without much added costs, the SEC does not require these companies to provide third party assurance on the XBRL documents filed. Further, the SEC is not holding these companies liable for any XBRL filing errors if the filed XBRL documents represent the standard reports when viewed using the SEC viewer.

XBRL is a set of rules and specifications that provide XML (Extensible Markup Language) tags for financial and business data using accepted financial reporting standards and terms (XBRL International).

${ }^{[1]} \mathrm{XBRL}$ is also referred to as Interactive Data, a term used by the SEC. 
Accounting researchers and proponents of XBRL document that the use of XBRL to create financial and business reports leads to cost savings and greater transparency, signals superior corporate governance, and has the potential to influence users' processing and acquisition of financial information (Eccles et al., 2001; Bovee et al,. 2002; Hannon, 2002; Weber, 2003; Hodge et al., 2004). Despite these advantages, there are several risks of error related to creating XBRL documents. When financial statements are prepared using XBRL, the usual risks of error related to the preparation of financial statements are present, but there are additional risks related to the use of the appropriate taxonomies and the accurate mapping of the accounts to the tags (Debreceny and Gray, 1999; The CICA, 2005; Gray and White, 2005; XBRL International AWG, 2006; Plumlee and Plumlee, 2008; Boritz and No, 2009; Bartley et al., 2011). There is subjectivity associated with the relevance of the tag, the taxonomy used, the relevance and/or completeness of a potential extension and possibly the overall appropriateness of the tag. These errors could potentially lead to the misrepresentation of company disclosures, which may negatively impact investors' decisions and the company's reputation (Bartley et al., 2011; Plumlee and Plumlee, 2008).

Even though the SEC does not require third party assurance on XBRL documents, the need to address the impact of XBRL on audit and assurance is gradually gaining prominence. The accountancy bodies within the XBRL International Consortium, such as the Assurance Working Group, (AWG) and the Public Company Accounting Oversight Board (PCAOB) recognize the need to investigate the challenges XBRL poses for the auditing profession.

In May, 2005, the PCAOB released Staff Q \& A's related to the attest engagements regarding XBRL data furnished under the SEC's XBRL Voluntary Financial Reporting Program under the EDGAR system. The Staff Q $\&$ A provides guidance to auditors who might be engaged to report on whether the XBRL data accurately reflects the corresponding information in the official EDGAR filings. These developments in the implementation of XBRL in the US suggest that the regulatory bodies are anticipating and considering the need for assurance of XBRL tagged financial statements. Yet, there is much debate and discussion amongst practitioners, regulators and academics about the importance of assurance, the level of assurance needed on XBRL documents, and the challenges it will create for the auditing profession such as increased costs for implementation and training of auditors and modifying the audit process (Bartley et al., 2011; Plumlee and Plumlee, 2008).

We conducted a survey of CPAs nationally to better understand their level of XBRL knowledge, and their perceptions about the importance of providing assurance on XBRL-tagged documents and the level of assurance needed. The results suggest that accountants and auditors believe that assurance on XBRL financial statements is important. The results further suggest that accountants and auditors believe that they will need to adjust their auditing methods to incorporate the use of XBRL information in the audit process and that independent assurance provided on XBRL information will improve the accuracy and reliability of the XBRL tagged financial statements. The results also show that participants ranked the assurance on accuracy and completeness assertions as being the most important and assurance on validity and well-formedness being the least important. Thus, suggesting that auditors are considering what form/type of assurance report on XBRL financial statements will be useful to investors. The findings have important implications for the audit profession, as the implementation of XBRL has the potential to not only expand the role of the auditor to include auditing their client's application of XBRL tags, but might also influence the cost and time involved to conduct audit services.

This paper is organized as follows. Section II explains the background and development of the research question. Section III describes the research method and results. Section IV summarizes and discusses the conclusions of this study.

\section{BACKGROUND AND DEVELOPMENT OF RESEARCH QUESTION}

\section{XBRL and the need for assurance}

XBRL is an XML-based specification for the electronic exchange of information using tags to identify individual data elements. The extensible aspect of XML enables any company to create its own tags for reporting any information, including financial data. XBRL is a standard methodology for using XML technology specifically for financial and business reporting to improve the comparability between XML-based financial documents. The 
XBRL specification, taxonomy, instance document and style sheets, are four important components to understand the use of XBRL in the reporting process ${ }^{[2]}$ and the resulting need for assurance.

The XBRL Specification provides the framework and requirements for using XML technology to create XBRL taxonomies and XBRL instance documents. The specification lays out the technical details explaining how XBRL works and cannot be edited by users. There is only one XBRL specification worldwide - version 2.1.

A Taxonomy is a dictionary describing the main data elements (numbers or text) such as items like cash, accounts receivable, accounts payable, inventory, etc. to create an instance document for a specific type of financial or business reporting (XBRL International AWG 2006). Taxonomies contain the concepts and interrelationships used in a particular type of business reporting (e.g. U.S. GAAP) and allow the creation of business or financial reports along with the instance documents. The extensible nature of XBRL allows the use of multiple taxonomies together, to support the diverse reporting methods across industries. Although most of the organizations in the U.S. could use the taxonomies developed by the XBRL consortium, research in XBRL shows that depending on their needs, an organization can create a completely new taxonomy or create an extension taxonomy to supplement the existing taxonomy (Bovee et al., 2002; Gray and White, 2005; XBRL International AWG, 2005, 2006).

Instance Documents are computer readable documents that consist of a collection of data tagged according to the concepts found in the taxonomies being used (XBRL International AWG, 2006). These tagged data are mapped to the taxonomy, using software tools intended for this purpose. These instance documents are currently being filed by the largest 500 companies in addition to traditional financial statements.

However, the instance document is not readable by a common user. A Style sheet is needed in order to make the raw XBRL data in the instance documents readable to the average person in a word, .pdf or spreadsheet format. A style sheet is a program that provides instructions on how to display the data in the instance documents. Analysts and other users can then use the style sheet to download the instance document and import the data into their own analytical tools and prepare their own comparative reports. Thus, users can consolidate information about numerous companies from numerous websites for analysis and experience the advantages of XBRL. Therefore, it is important that the instance document is appropriately mapped to the relevant taxonomy, according to the XBRL specification for the generation of reliable XBRL reports.

While assurance on the instance documents is not mandatory in the U.S. or internationally, researchers and proponents of XBRL suggest that such assurance is important in the adoption and implementation of XBRL (Boritz and No, 2003, 2004; The CICA, 2005; Gray and White, 2005; Farewell, 2006; XBRL International AWG, 2006; Plumlee and Plumlee, 2008; Bartley et al., 2011). The following discussion highlights some of the factors that create a need for assurance on instance documents.

\section{Risks of Error}

The following are factors that create a need for assurance in the current XBRL reporting environment where traditional financial statements are being converted to XBRL format, and both formats are available to external users ${ }^{[3]}$.

Use of Appropriate Taxonomy: The selection of an appropriate taxonomy from the several taxonomies that are available is an important issue. The taxonomy must be appropriate for the intended use of the financial reports produced. Use of an inappropriate taxonomy will lead to inappropriate tagging and misrepresentation of financial statements.

\footnotetext{
${ }^{[2]}$ See Appendix A for the relationship among these components.

[3] There is a great probability that XBRL financial reports will become the primary financial statements in the future, rather than a secondary format containing the same information as the original statements. Such a situation will call for greater assurance on XBRL tagged data.
} 
Misapplication of XBRL tags: Two general types of human errors could occur here:

Human Error because of incorrect judgment: Management or the person doing the mapping uses his or her judgment to determine whether a specific XBRL tag is appropriate. Although software programs will automatically do much of the tagging, the person responsible for the mapping still decides how an item should be classified based on the taxonomy selected. So, the fact that management decides how an item should be classified leaves room for subjectivity and manipulation (Jones and Willis, 2003; Boritz and No, 2003, 2004; Cohen, 2004; Hodge et al. 2004; The CICA, 2005; Gray and White, 2005; White 2006; XBRL International AWG, 2006). This point highlights the importance of assurance of the XBRL-based financial statements, because technology or software programs cannot ensure correct usage of the taxonomies.

Errors Similar to typos or Mechanical Errors: Organizations could incorrectly use software programs when tagging the data. For example, companies could use a drag and drop software as a tool to create an instance document and in the process, can inadvertently drag the source label to the wrong XBRL tag. This would not be an XBRL judgment error because the person did select a legitimate tag, but it was simply the wrong tag for that particular item (Gray and White, 2005; The CICA, 2005). For example, cash and cash equivalents could be incorrectly dragged and dropped on the accounts receivable tag. Other errors such as selection of incorrect time periods, dollar amounts, signs, and units of measurement could also be made.

Extensions or Custom Tags: Many organizations develop extensions to the taxonomies they started with, in order to represent facts that are specifically related to their companies or their industry. Furthermore, based on the evidence provided by Bovee et al. (2002), it is clear that there could be differences in the way companies might have extended their taxonomies. These extensions may not be comparable to the standard taxonomy created by the XBRL Consortium. For example, some companies may want to provide more disaggregated information than the standard taxonomy provides. Or, some companies may create extensions that can be related to more than one main item in the standard taxonomy. Moreover, the organization creates the extension taxonomy and asserts that it is in compliance with a standard taxonomy developed externally by the XBRL consortium. In such cases, it is imperative to consider the relevance, use, and/or completeness of such extension taxonomies, and to ascertain whether the extension taxonomy was properly created and structured to report new concepts and relationships that are not included in the standard taxonomy (Gray and White, 2005; The CICA, 2005; XBRL International AWG, 2006).

Results of recent research which have examined the XBRL filings of companies during the SEC's Voluntary Filing Program (VFP) prior to 2009 provide evidence for the occurrence of a high number of errors in the XBRL submissions by the initial voluntary filers. Bartley et al. (2011) examined 22 companies' initial voluntary XBRL Form 10-K filings in 2006 and the 2008 filings of 11 of the 22 companies that also filed in 2006 in order to identify the types and frequency of errors made by these initial voluntary filers, and whether the frequency of errors changed between 2006 and 2008 concurrent with the improvements in the XBRL coding software, the U.S. GAAP taxonomy and the XBRL protocols. They found that companies made numerous mapping errors (or as explained above, misapplication of XBRL tags) where the financial statement concepts have been incorrectly matched with the XBRL elements, companies have made straight-forward data entry errors, used incorrect time periods, incorrect signs, incorrect rounding, and numerous extension tag errors.

They also found that the number of errors decreased dramatically by 2008 and attribute this decrease in errors to the improvements in the XBRL protocol and U.S. GAAP. However, they caution that the persistence of errors in the third year for the 11 companies in their sample highlights the difficulty of preparing accurate XBRL documents for GAAP-based financial statements. They suggest that assurance on XBRL documents might lead to accuracy and reliability, but caution that the implementation would create additional challenges.

Boritz and No (2009) conducted a mock audit on the October 2005, Form 10-Q filing of United Technologies Corporation, which had been formally reviewed by PriceWaterHouseCoopers LLP. In their mock audit, they conducted a manual comparison of the XBRL document with the official 10-Q filing, which took about 63 hours to complete. They identified several problems such as redundant elements, missing totals and misspellings. Overall, they found that the 10-Q XBRL related documents were a complete and accurate reflection of the official $10-\mathrm{Q}$, but were unable to assess whether the XBRL documents were a fair presentation in accordance with GAAP because there were no guidelines for making such an assessment for certain sections such as the company's 
taxonomy extensions. Boritz and No (2008) used XBRL validation software to examine the filings made during the SEC's VFP and found that the frequency of syntax and other errors detected by these validation tests increased from 2005 through 2007. Consistent with Boritz and No (2008), Plumlee and Plumlee (2008) also note that validation software cannot detect judgment errors made in XBRL documents such as the appropriateness of the element selected.

Further, Boritz and No $(2003,2004)$ note that XBRL does not take into account whether XBRL tagged data is reliable. They explain that the reliability of XBRL tagged financial data depends on the reliability of the processes used to create an XBRL instance document and the nature, extent and timing of assurance procedures performed on that information. Similarly, Nicalaou et al. (2003) note, that the emergence of web-based data exchange using XBRL has created a demand for increased accountability and control among transacting parties. They state that the provision of assurance services has the potential to satisfy this demand.

In summary, these studies provide evidence that due to these potential risks of error when XBRL is used to generate financial statements, there is subjectivity associated with the relevance of the tag, the taxonomy used, the relevance and/or completeness of a potential taxonomy extension and possibly the overall appropriateness of the tag. Although they suggest that mandatory assurance on XBRL documents is imperative for producing reliable and accurate date, they also draw attention to the challenges that the audit profession could face with the implantation of mandatory assurance such as training, costs, etc. The aim of this study is to gather information about accountants' level of knowledge of XBRL and their perceptions about the importance of providing assurance and the level of assurance needed. Our aim is to answer the following research question:

RQ1: Do accountants and auditors believe that providing assurance on XBRL documents is important?

\section{RESEARCH METHOD AND RESULTS}

An online survey questionnaire was used to gather data to answer the research question of this study. CPAs at all levels of an audit team from staff auditors to partners were invited to participate in the survey. The survey took about 15 minutes to complete and gathered information about participants' level of knowledge and awareness about XBRL, perceptions about the importance, relevance, and need for assurance on XBRL financial information. Respondents indicated their agreement or disagreement to the statements using a 7-point Likert scale. The survey also asked for demographic information concerning respondents' education, work experience, and level of knowledge of and training in XBRL. All responses were anonymous and could not be linked to individual participants in any way. The email request to participate in the survey was sent out to 900 CPAs nationally on December 1, 2009. Follow up email reminders were sent in January and February 2010. The email asked the recipients to share the email with other CPAs in their office. Eighty four individuals responded to the survey, of which 39 fully complete and usable responses were obtained. Table 1 provides the demographics of the sample and information about participants' level of XBRL knowledge.

As shown on Table 1, Panel A, 62 percent of the participants are CPAs and 74 percent work in public accounting. On average, participants in the sample working in public accounting have between one and two years experience while CPAs working in industry have over 11 years of professional experience. Table 1, Panel B provides data on participants' level of knowledge of XBRL. Overall, $51.3 \%$ of participants suggest that they have no knowledge of XBRL or are aware of XBRL but know few details. Additionally, 17.9\% of the participates indicate they possess a moderate level of knowledge of XBRL and 30.8\% indicating a high level of knowledge. Panel C of Table 1 shows the level of training participants have received in XBRL. The participants report that $51.3 \%$ have received no or well below average levels of training while $17.9 \%$ and $30.8 \%$ indicate they have received average or well above average levels of training, respectively. In Panel D of Table 1, the results further suggest that the participants believe they do not have the skills, expertise and training to provide assurance on XBRL (mean $=3.51$; s.d. $=2.16$ ). 
Table 1

Sample Demographics

$[\mathbf{N}=39]$

\begin{tabular}{|c|c|c|c|c|}
\hline \multicolumn{5}{|l|}{ Panel A } \\
\hline \multicolumn{3}{|l|}{ Currently Employed In: } & $\mathbf{N}$ & Percentage \\
\hline \multicolumn{3}{|l|}{ Public Accounting } & 29 & $74.4 \%$ \\
\hline \multicolumn{3}{|l|}{ Industry } & 6 & $15.4 \%$ \\
\hline \multicolumn{3}{|l|}{ Government } & 2 & $5.1 \%$ \\
\hline \multicolumn{3}{|l|}{ Non-profit } & 2 & $5.1 \%$ \\
\hline \multicolumn{3}{|l|}{ Total } & 39 & $100.0 \%$ \\
\hline Years of Experience In: & $\mathbf{N}$ & Mean & $\begin{array}{l}\text { Standard } \\
\text { Deviation }\end{array}$ & Range \\
\hline Public Accounting & 39 & 1.41 & 0.86 & $1-4$ \\
\hline Industry & 34 & 11.36 & 11.27 & $0-40$ \\
\hline Government & 9 & 6.67 & 6.87 & $0-20$ \\
\hline Non-profit & 4 & 6.75 & 6.65 & $0-15$ \\
\hline Certification & & $=62 \%$ & $38 \%$ & \\
\hline
\end{tabular}

\begin{tabular}{|c|c|c|}
\hline Panel B & & \\
\hline Participant's Level of Knowledge of XBRL & & \\
\hline Level & Number & Percentage \\
\hline I have no awareness of XBRL (beyond that provided in the introduction to this survey). & 3 & $7.7 \%$ \\
\hline I am aware of XBRL but know few details. & 17 & $43.6 \%$ \\
\hline I have a moderate level of knowledge of XBRL. & 7 & $17.9 \%$ \\
\hline I have a high level of knowledge of XBRL. & 12 & $30.8 \%$ \\
\hline Total & 39 & $100.0 \%$ \\
\hline
\end{tabular}

\begin{tabular}{|l|c|c|}
\hline Panel $\boldsymbol{C}$ & \multicolumn{2}{l|}{ Number } \\
\hline Participant's Level of Training Received in XBRL & 3 & $7.7 \%$ \\
\hline None & 17 & $43.6 \%$ \\
\hline Well below average. & 7 & $17.9 \%$ \\
\hline Average & 12 & $30.8 \%$ \\
\hline Well above average. & $\mathbf{3 9}$ & $\mathbf{1 0 0 . 0 \%}$ \\
\hline$\quad$ Total & & \\
\hline
\end{tabular}

\begin{tabular}{|l|c|c|}
\hline Panel $D$ & \multicolumn{2}{|l|}{} \\
\hline Participant's Expertise to Provide XBRL Assurance & $\begin{array}{c}\text { Standard } \\
\text { Deviation }\end{array}$ \\
\hline Response Scale: (1) completely disagree - (7) completely agree & Mean & 3.51 \\
\hline I believe that I have the expertise to provide assurance on XBRL data. & 2.16 \\
\hline
\end{tabular}

Table 2 provides data about participants' beliefs about the importance of assurance on XBRL financial statements. The data suggests that participants strongly agree that assurance should be provided on the XBRLtagged financial statements and footnotes (mean $=6.03$, s.d. $=1.22$ ), rather than on the financial statements only (excluding the footnotes) (mean $=2.28$, s.d. $=1.52$ ). The data also suggests that participants moderately agree the assurance provided should be positive assurance as part of the regular audit (mean $=4.72$, s.d. $=2.14)$ rather than as a separate attestation service with positive assurance $($ mean $=3.69$, s.d. $=1.95$ ) or as a review service providing a moderate level of assurance $($ mean $=3.28$, s.d. $=1.93)$. They also strongly agree that auditors will adjust their auditing methods to incorporate the use of XBRL information in the audit process $($ mean $=5.36$, s.d. $=1.16)$ and that independent assurance provided on XBRL information will improve the quality of the information $($ mean $=$ 5.67 , s.d. $=1.3$ ). There is evidence for slight agreement that the use of XBRL information by auditors will increase the efficiency in the audit process (mean $=4.67 ; 1.67)$. 
Table 2

Participant's Beliefs about the Importance of Assurance on XBRL Financial Statements

[N=39]

Response Scale: $(1)=$ completely disagree $-(7)=$ completely agree

\begin{tabular}{|c|c|c|}
\hline & Mean & $\begin{array}{l}\text { Standard } \\
\text { Deviation }\end{array}$ \\
\hline Belief that assurance should be provided on the financial statements only & 2.28 & 1.52 \\
\hline Belief that assurance should be provided on the financial statements and footnotes & 6.03 & 1.22 \\
\hline \multicolumn{3}{|l|}{ Assurance should be: } \\
\hline part of a regular audit of the financial statements providing positive assurance & 4.72 & 2.14 \\
\hline an attestation engagement separate from the audit providing positive assurance & 3.69 & 1.95 \\
\hline a review engagement separate from the audit providing moderate assurance & 3.28 & 1.93 \\
\hline $\begin{array}{l}\text { Belief that auditors will adjust their auditing methods to incorporate XBRL data in the audit } \\
\text { process }\end{array}$ & 5.36 & 1.16 \\
\hline $\begin{array}{l}\text { Belief that independent assurance on the XBRL data will improve the quality of the } \\
\text { information }\end{array}$ & 5.67 & 1.3 \\
\hline Belief that use of XBRL will increase efficiency in the audit process & 4.67 & 1.67 \\
\hline
\end{tabular}

Table 3 provides insights on auditors' and accountants' perceptions of the importance of the assertions for XBRL assurance. There is good agreement that adequate criteria do not exist to provide assurance on XBRL information $($ mean $=3.49$, s.d. 1.57$)$ and strong agreement that criteria could be developed $($ mean $=5.74$, s.d. 1.27$)$. Table 3 also shows participants' perceptions about the importance of assertions with respect to assurance on XBRL data. The table shows the participants believe accuracy and completeness are the most important assertions on XBRL data and rank validity and well-formedness as the least important.

Table 3

Importance of the Assertions for XBRL Assurance

[N=39]

Response Scale: $(1)=$ completely disagree $-(7)=$ completely agree

\begin{tabular}{|l|c|c|}
\hline & \multicolumn{1}{|c|}{$\begin{array}{c}\text { Standard } \\
\text { Deviation }\end{array}$} \\
\hline Belief that adequate criteria for assertions currently exists to provide assurance & 3.49 & 1.57 \\
\hline Belief that adequate criteria for assertions could be developed & \multicolumn{2}{|c|}{5.74} \\
\hline \multicolumn{2}{|l|}{1.27} \\
\hline Belief regarding the importance of the following assertions if assurance is provided on XBRL information: \\
\hline Response Scale: (1) = least importance; (7) most importance] & 5.76 & 1.52 \\
\hline Accuracy & 5.07 & 1.74 \\
\hline Completeness & 4.84 & 1.39 \\
\hline Existence & 4.34 & 1.76 \\
\hline Proper taxonomies & 4.21 & 2.17 \\
\hline Proper extensions & 4.21 & 2.12 \\
\hline Valid extensions & 3.92 & 1.47 \\
\hline Validity and well-formedness & 2 & \\
\hline
\end{tabular}

\section{SUMMARY AND CONCLUSIONS}

This paper reports on the results of an online survey questionnaire to gather information about accountants' and auditors' perceptions about the importance of assurance on XBRL financial statements. The results suggest that accountants and auditors believe that assurance on XBRL financial statements is important. The results further suggest that accountants and auditors believe that they will need to adjust their auditing methods to incorporate the use of XBRL information in the audit process and that independent assurance provided on XBRL information will improve the accuracy and reliability of the XBRL tagged financial statements. Participants were also asked to rank the importance of assurance criteria on XBRL financial statements such as assurance on the accuracy, completeness, 
existence, proper taxonomies, proper extensions, valid extensions and validity and well-formedness. The results show that participants ranked assurance on accuracy and completeness assertions as being the most important and assurance on validity and well-formedness being the least important.

Overall, this survey provides initial evidence on accountants' perceptions about the importance of assurance and provides some insights on the criteria for providing assurance on XBRL financial statements. The results also show that auditors have limited knowledge, have received well below average training in XBRL, and that they do not have the skills, expertise and training to provide assurance on XBRL.

Based on our results which indicate that participants have a low level of knowledge in XBRL, we argue that the limited response to our survey could be attributed to the lack of awareness of XBRL and its potential influence on the audit profession amongst accountants and auditors. Despite this limitation, the results of this study provide relevant and timely evidence to regulators, practitioners and academic researchers on the assurance implications of XBRL. Regulators and accountancy bodies within the XBRL International Consortium (XBRL International AWG), call for research on examining the need for assurance on XBRL data, to gain an understanding of the nature and scope of the market demand for assurance services. This study contributes towards understanding the current state of the assurance implications of XBRL, and its possible influence on the rate of adoption and implementation in the U.S. Examining the challenges mandatory assurance on XBRL would create such as training costs incurred to train auditors to provide assurance, costs incurred to modify the audit process, and the costs to filers, would be an interesting issue for future research.

\section{ACKNOWLEDGEMENTS}

We thank Mike Willis (PriceWaterhouseCoopers; Founding member XBRL International) and Liv Watson (Chief Product Officer at XBRL International) for their valuable suggestions.

\section{AUTHOR INFORMATION}

Dr. Venkatesh is an assistant professor at the University of Nebraska at Omaha. Professor Venkatesh's teaching interests are managerial accounting and financial accounting. Her research interests lie in the areas of managerial accounting and auditing. She is focused on understanding the judgment and decision-making behavior of accountants and auditors. Her research work in the area of budgeting draws from theories in psychology and organizational behavior. Her research interests also include examining the effect of XBRL on the audit process and auditors judgments. Before entering academe, she worked as a certified financial manager in the financial services industry. E-mail: rvenkatesh@unomaha.edu

Dr. Armitage is the Distinguished Alumni Accounting Professor at the University of Nebraska at Omaha. Professor Armitage's teaching interests include auditing, financial accounting and fraud examination, and he has received awards for his teaching. His research involves auditing and accounting education issues with over 35 publications and 30 presentations. Dr. Armitage has significant experience working outside the USA. He has taught classes at foreign universities, consulted on curriculum issues, and given presentations to practicing auditors and accountants. He was recently awarded a Fulbright Senior Specialists grant to teach graduate auditing courses in Moldova, has served on the Fulbright Peer Review Committee, and served as a member of the Auditing and Attestation Subcommittee for the CPA Exam. E-mail: jarmitage@ unomaha.edu. Corresponding author.

\section{REFERENCES}

1. Bartley, J., Chen, Al Y. S., and Taylor, E.Z. (2011). A Comparison of XBRL Filings to Corporate 10-Ks: Evidence from the Voluntary Filing Program. Accounting Horizons, Vol. 25, No. 2, pp. 227 - 245.

2. Boritz, J. E., \& No, W. G. (2009). Assurance on XBRL-Related Documents: The Case of United Technologies Corporation. Journal of Information Systems, Vol. 23 No. 2, pp. 49-79.

3. Boritz, J. E., \& No, W. G. (2008). The SEC's XBRL Voluntary Program on Edgar: The Case for Quality Assurance. Current Issues in Auditing, Vol. 2 No. 2, pp. 36-50. 
4. Boritz, J.E., and No, W.G. (2003), Assurance Reporting for XBRL: XARL (Extensible Assurance Reporting Language). PriceWaterHouse Coopers Research Monograph 17-31.

5. Boritz, J.E., and No, W.G. (2004), Assurance Reporting for XBRL: XARL (Extensible Assurance Reporting Language). CAP Forum on E-Business Vol. 3No. 2, pp. 207-233.

6. Bovee, M., Ettredge, M. L., Srivastava, R. P., and Vasarhelyi, M. A. (2002), Does the Year 2000 XBRL Taxonomy Accommodate Current Business Financial-Reporting Practice? Journal of Information Systems Vol. 16 No. 2, pp.165-182.

7. Cohen, E.E. (2004), Compromise or Customize: XBRL's Paradoxical Power Canadian Accounting Perspectives Vol. 3 No. 2, pp. 187-206.

8. Debreceny, R., and Gray, G.L. (1999) Financial Reporting on the Internet and the External Audit. The European Accounting Review Vol. 8 No. 2, pp. 335-350.

9. $\quad$ Eccles, R., Herz, R., Keegan, E., and Phillips, D. (2001). The ValueReporting Revolution. John Wiley \& Sons, Inc. New York.

10. Farwell, S. M. (2006). An Introduction to XBRL through the Use of Research and Technical Assignments Journal of Information Systems Vol. 20 No. 1, pp. 161-185.

11. Gray, G. and White, C. E. (2005) XBRL: Potential Opportunities and Issues for Internal Auditors. The Institute of Internal Auditors Research Foundation.

12. Hannon, N. (2002). Accounting Scandals: Can XBRL Help? Strategic Finance (August): pp, 61-62.

13. Hodge, F. D.; Kennedy, J. J., and Maines, L. A. (2004). Does Search Facilitating Technology Improve the Transparency of Financial Reporting? The Accounting Review Vol. 79 No. 3, pp. 687-703.

14. Jones, A. and Willis, M. (2003). The Challenge of XBRL: Business Reporting for the Investor. Balance Sheet Vol. 11 No. 3, pp. 29-37.

15. Nicolaou, A. I., Lord, A.T., and Liu, L. (2003). Demand for Data Assurances in Electronic Commerce: An Experimental Examination of Web-Based Data Exchange Using XML. PriceWaterHouseCoopers Research Monograph pp. 32-42.

16. Plumlee, R. D., \& Plumlee, M. A. (2008). Assurance on XBRL for Financial Reporting. Accounting Horizons, Vol. 22 No. 3, pp. 353-368.

17. Public Company Accounting Oversight Board. (2005). Staff Questions and Answers Attest Engagements Regarding XBRL Financial Information Furnished Under the XBRL Voluntary Financial Reporting Program on the EDGAR System. (Public Accounting Oversight Board) Retrieved December 2006, from http://pcaobus.org/standards/staff_questions and answers/2005/05-25\%20.pdf

18. SEC. (2009). Interactive Data to Improve Financial Reporting. Securities and Exchange Commission. Retrieved January 2010, from http://www.sec.gov/rules/final/2009/33-9002.pdf

19. The Canadian Institute of Chartered Accountants (2005): Audit and Control Implications of XBRL (Prepared by the Information Technology Advisory Committee) December.

20. Weber, R. A. (2003). XML, XBRL, and the Future of Business Reporting. In S.J. Roohani (Ed.), Trust and Data Assurance in Capital Markets: The Role of Technology Solutions Bryant College pp. 3-6

21. White, C. E. (2006). The Accountant's Guide to XBRL.

22. XBRL International (Assurance Working Group) (2005). Assurance Implications of Business Reporting with XBRL. November.

23. XBRL International (Assurance Working Group) (2006). Interactive Data: The Impact on Assurance. November.

24. XBRL International www.xbrl.org 


\section{APPENDIX A}

Relationship among XBRL Components
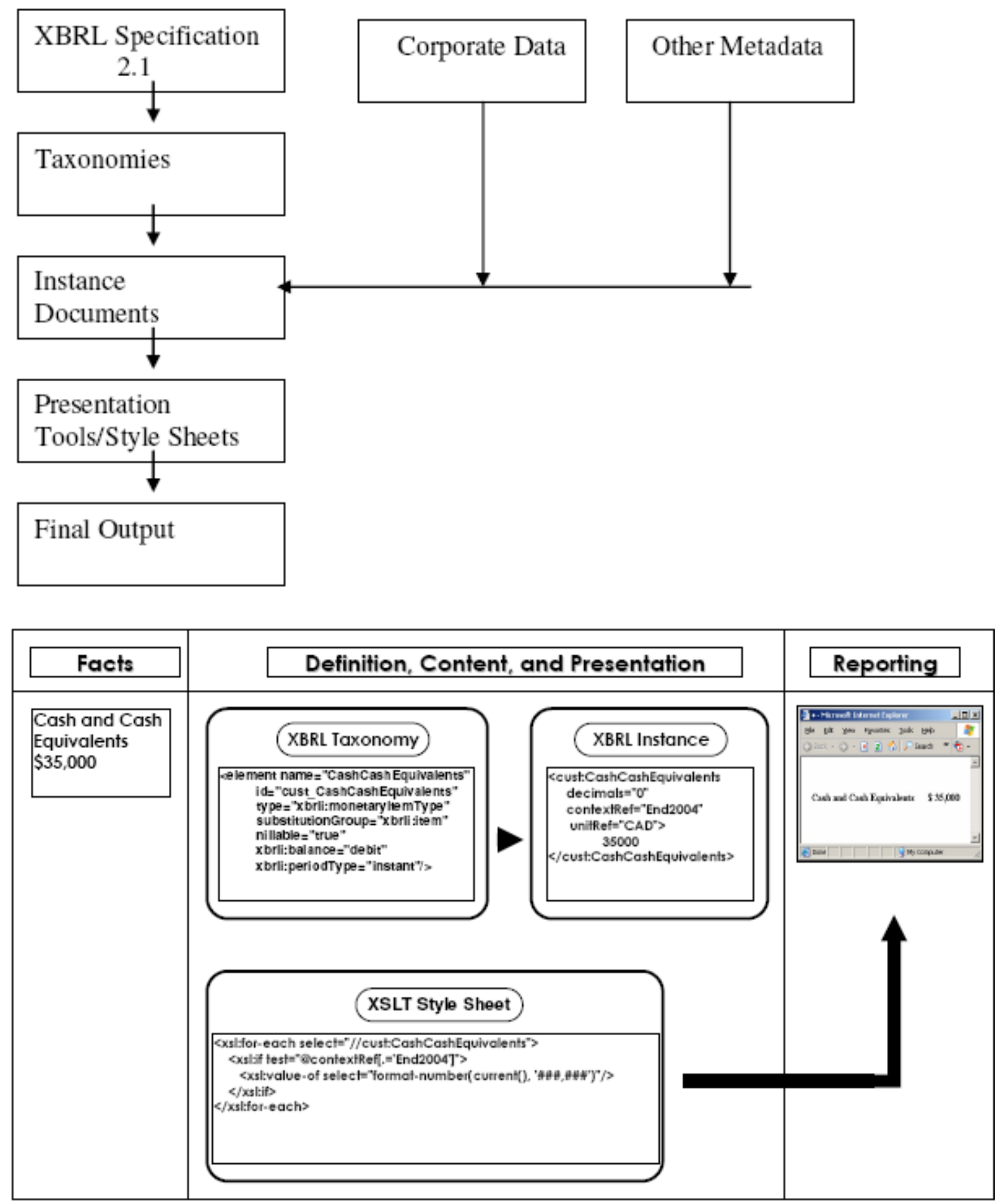

Source: http://www.xbrl.org 